\title{
Identifying And Assessing Adverse Selection
}

\author{
Stephen A. Kane, (E-mail: skane@suffolk.edu), Suffolk University
}

\begin{abstract}
This paper uses examples to demonstrate the generality of issues resulting from the heterogeneity of a population. Heterogeneity is fundamental to the marketing strategy of any firm. If one market segment is more expensive to service, then members of that segment might be charged higher prices or be left to one's competitors. We pay particular attention to heterogeneity issues in financial services, specifically, insurance underwriting, lending, and investing. We examine techniques that practitioners use to assess heterogeneity in a population with respect to loss events. We employ the $\chi^{2}$-goodness of fit test to assess whether observations in risk classes (sub partitions of population) are relatively homogenous. We use a sign-rank test to assess whether or not two loss distributions from different risk classes were drawn from the same probability distribution. We discuss how mutual ownership and price fixing have evolved as built-in safety nets to cope with modeling limitations.
\end{abstract}

\section{IDENTIFICATION}

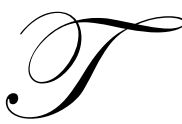

his paper uses examples to demonstrate the generality of issues resulting from the heterogeneity of a population. Heterogeneity is fundamental to the marketing strategy of any firm. If one market segment is more expensive to services, then members of that segment might be charged higher prices or be left to one's competitors. We pay particular attention to heterogeneity issues in financial services, specifically, insurance underwriting, lending, and investing. We demonstrate the generality of adverse (beneficial) selection issues through examples. Where applicable, we distinguish pure adverse selection concerns from moral hazard problems, in particular, principal-agent conflicts.

\section{Definitions}

When two parties in a transaction, or more generally a contract, have access to the same observations and analysis, we say there is symmetric information. When this is not the case, we say there is asymmetric information. Often, one party is better informed than the other party - and this asymmetry may induce adverse selection and moral hazard concerns that we describe below.

An adverse (beneficial) selection is a non-representative, that is, biased sample drawn from a heterogeneous population that is adverse (beneficial) to an economic agent. For definiteness, we need to specify how we assess the heterogeneity and in what sense we mean the selection is adverse (beneficial).

Principal-agent problems occur when one party, the principal, contracts with a second party, the agent, to delegate a task to the principal. The agent chooses to maximize his/her own benefit from the contract at the expense of the principal's benefit. The principal's benefit cannot be completely protected due to the principal's inability to monitor the agent perfectly (Kane 1999A).

Principal-agent problems are moral hazard problems. Defined from the principal's perspective, a moral hazard problem is a disadvantageous change in an agent's behavior due to the existence of an implicit or explicit contract. For example, an agent who buys fire insurance from an insurance company, the principal, may no longer be as prudent about preventing fires, because the agent is insured against a fire loss. Consequently, the probability 
of that agent incurring a fire loss has increased due to the existence of the contract (Kane 1999A). Indeed, this is one reason why insurance companies often insist on deductibles that keep the policy holder partially exposed to losses.

\section{Diverse Examples}

\section{Market for Lemons}

George Akerlof (1970) wrote a 2001 Noble prize winning paper on adverse selection. He argued that very young but used cars tend to be lemons (defective). After all, why would someone trade in a car that was less than a year old unless it was a lemon? He suggested that is one reason why new cars lose over $10 \%$ of their value when a customer drives them off the car lot. Akerlof also suggested that warrantees from credible sources will lead to price premiums, because they will reduce uncertainty for buyers.

\section{Senior Communities}

Some counties seek to develop communities for older citizens who tend to require less expensive services at the county level. Crofton Colony in Anne Arundel County MD, located between Baltimore MD and Washington DC, is an example. Through deed restrictions, homeowners agree to have no one under eighteen living in their household for more than six months. Thus, there is less need for primary and secondary education services. Older citizens do have a greater need for healthcare, but this is less expensive and is funded more at the city, state, and federal levels. Consequently, Anne Arundel County can maintain lower real estate taxes than surrounding counties, because the county has garnered a beneficial selection of older citizens.

\section{Teacher Evaluations}

At Suffolk University, as at many institutions of higher learning, the administration requires that teachers hand out evaluation forms each semester to students. Teachers may desire a higher score on their evaluations from their students. At Suffolk University the teacher selects an evaluation day near the end of the semester. The author has found it beneficial to strategically choose when to hand out the student evaluations. Through empirical trial and error, the author has found the class before Thanksgiving vacation during fall semester to generate a beneficial selection of students attending class (the more serious students), and the last class before the final or immediately before the final exam (all the students) to generate a less beneficial selection of students.

Instructors may receive better teaching evaluations from students in an elective course taken by students majoring in the field than in required course taken by many students who are majoring in other fields. With an elective course, the students often choose to take the course with an instructor over taking other elective courses with other instructors (self-selection). Because the elective course is in the students' major, the students may be more interested in the subjects. Further, the students may take more care in selecting the instructor than non-majors in required courses. We note that the material is more likely to be in the instructor's area of expertise. Thus, the instructor may teach better, too. This last reason for better evaluations is not beneficial selection per se, because it may not directly affect the population of students evaluating an instructor.

\section{Compensation for Professors}

Slackoff State University (SSU) ${ }^{1}$ has a heterogeneous faculty. Some members are highly productive while other members are much less so. In order to "prune the dead wood," SSU's President is planning to offer an early retirement package. Rumors about the package have circulated among the faculty. A few less productive professors plan to accept SSU's offer and retire, while many of the most productive professors plan to do so and accept similar positions at other universities.

\footnotetext{
${ }^{1}$ Slackoff State University is the home of the beloved mascot, Sammy the Sloth.
} 
As an economist, what advice should one give SSU's President? Less productive members of the faculty have little reason to leave while more productive professors will take the package and leave. Thus, there will be an adverse selection problem. It may appear that SSU has acquired an adverse draw from the population of professors, but the lack of productivity may be due to a principal-agent conflict and not an adverse selection problem per se. A better solution might be for the principal (University Administration) to monitor the agents (Professors) better. Less productive professors may be identified and let go if they don't have tenure. ${ }^{2}$ If they do have tenure, they can be paid less or at least not given raises. Further, there should be a way to give incentives such as cash awards and bonus programs to increase the productivity, that is, to tie the remuneration of professors to their production.

Additionally, SSU's mathematics department salary compensation scheme does not distinguish whether or not a professor is a theoretical or applied mathematician. This scheme has garnered an adverse draw of theoreticians who find SSU's compensation relatively attractive to other universities that pay theoreticians less than applied mathematicians. The salary difference at other universities may be attributable to the tendency of applied mathematicians: to have better employment opportunities themselves outside of academia, to garner better employment opportunities for their students, to sustain a research agenda longer, to be more able to garner outside funding, to be preferred by students as teacher due to their practical approach, and to be preferred by faculty in business, the sciences, and engineering as colleagues.

Again, as an economist, what advice should one give SSU's President? Similar to other universities, the compensation scheme might discriminate in favor of applied mathematicians over theoreticians. With a mathematics department dominated by theoreticians who would have substantial control over the hiring process, it may be difficult to hire and pay applied mathematicians more, since theoreticians may sabotage this process. Consequently, the President might establish an applied mathematics department in a separate college. ${ }^{3}$ The compensation scheme for the new department might have a lower base salary and have more incentives for garnering outside funding and for doing a quality job when teaching. This will make working in the applied department less attractive for a theoretician, but more attractive to an applied mathematics professor. Thus, it may be possible to attract a beneficial selection of applied mathematicians into the new department. When attrition does eliminate professors in the theoretical department, the administration might respond to student demand for courses and add positions for new professors in the applied department. Further, since the current salary of theoretical professors is likely to be much higher than similar theoretical mathematicians at other universities, the administration might not give raises to professors in the theoretical mathematics department until they begin to garner offers from other universities.

\section{Market Niches}

Due to the heterogeneity in market niches, there are adverse selection concerns.

\section{Pooling without Discrimination}

Many companies who underwrite life insurance contracts require applicants to undergo a medical examination. Based on the findings, a premium is established dependent on the health and future risks of the participant. Without requiring a physical, an insurance company might offer life insurance to almost everyone. Those not willing or able to pass a medical exam would be able to participate and obtain a life insurance policy. The insurance companies will have to charge significantly higher monthly premiums to be compensated for the increased risk. Customers may become loyal to their insurance company. The insurer may still prosper because its premiums are higher than that of companies who require physicals to separate customers into various risk classes with gradated premiums.

\footnotetext{
${ }^{2}$ Tenure is a guarantee of permanent job for the career of professor by a University.

${ }^{3}$ Indeed, would the salary of finance professors be significantly higher than the salary of economics professors if they were not in a separate college of business?
} 


\section{Creditworthiness}

The managing director for credit risk at a bank recommends to senior management that they raise the interest rates on their credit cards to increase profits. He theorizes that higher rates will mean higher revenues, but that costs will remain roughly the same. Unfortunately, by raising the interest rates, the managing director forced many of his profitable customers to leave the company, and to take with them their low default rates, to seek better arrangements elsewhere. This left behind those customers who were unable to leave because they have bad credit (high default risk). The default rate for the bank increased sharply for the remaining credit card customers. By increasing the rates, the managing director increased the probability of default on the remaining customers and lost profitable customers. These losses were not offset by the higher interest rates charged.

\section{Emerging Markets}

There are transparency and asymmetric information concerns with emerging stock and bond markets, for instance, in Eastern Europe. If investors cannot determine which companies are better due to a lack of quality information, the market may be forced to value good and bad companies similarly. This may mean that good companies may have to pay a higher cost of capital than if investors benefited from a better corporate governance regime.

This is not a pure adverse selection problem, however. There is not a strong corporate governance system in place, that is, legal infrastructure, accounting disclosure, recourse for debt holders in U.S. bankruptcy courts, insider trading restrictions, shareholder control over the board of trustees, well established stock market exchanges, and enforcement. Debt holders value enforceable covenants and recourse in bankruptcy proceedings. Managers may need to bond themselves better with shareholders' interest thus reducing principal-agent conflicts. While this bonding includes accounting disclosure that would improve transparency and reduce adverse selection concerns, there are other performance benefits derived from a better corporate governance regime. These performance benefits may result, in part, from executive stock options, more shareholder control of the board of trustees, and the potential for shareholder class action law suits in U.S. courts. These mechanisms help to align the interest of management with shareholders (Coffee 1999, Blodgett and Kane 2003).

\section{Interest Rate Risk}

We suppose a city has only two financial institutions, Vary Thrift and Fixy Bank. Both institutions offer customers the choice between an adjustable rate mortgage (varies with the rate on the ten year U.S. Treasury) and a fixed rate mortgage (interest rate does not vary over the life of the mortgage). Vary Thrift's chief economist forecasts that interest rates will go up in the future. Consequently, Vary Thrift substantially reduces the origination fee on their adjustable rate mortgage and substantially increases the fee for the fixed rate mortgage. Vary Thrift is trying to reduce the interest rate risk of its new loans by originating more adjustable mortgages. If Fixy Bank agrees with the forecast but does not react, it may not be in business very long -- especially if rates rise and sustain at that level for a long period of time. If Fixy Bank does not modify its business strategy, it may get an adverse draw of fixed rate mortgage customers. Fixed rate loans (assets) will not offset the higher rate depositors' payments (liabilities) unless Fixy Bank has hedged its interest rate risk. ${ }^{4}$ This scenario occurred in the 1970s and 1980s with many Savings and Loans who did not hedge their interest rate risk nor securitize many of the mortgages. ${ }^{5}$

\section{New Banking Entrant}

A large bank holding company might open a branch in a small town to drive an incumbent small bank out of business. The large bank might only have a slight advantage in economies of scope and scale over the incumbent

\footnotetext{
${ }^{4}$ We note that Fixy Bank may disagree with the prognosis of higher interest rates. Fixy Bank may make a calculated decision to cater toward fixed rate loans, speculating that interest rates fall or remain steady. If this is the case, then Fixy Bank will have garnered a beneficial selection of customers.

${ }^{5}$ This is less of a problem today, because most originators securitize many of the mortgages in response to risk-based capital requirements (Kane and Muzere, 2004).
} 
small bank, however, because the incumbent bank may outsource to obtain a similar level of economies of scope and scale (Kane, Laosinchai, and Muzere, 2003). The small bank has an informational advantage and a loyal customer base (Reichheld, 2001). The new entrant would likely garner an adverse draw of less profitable customers from the small bank due to its informational disadvantage.

\section{Cross-Selling}

Chase has not been able to cross-sell its customer as well as many of its competitors who tend to have less wealthy and creditworthy customers. Why? There is a lot of competition for wealthy and creditworthy customers. These customers tend to have well-established relationships with insurance agents, stock brokers, and mutual fund managers (Reichheld, 2001). Competition also reduces the ability to cross-sell and the profitability resulting from cross-selling.

\section{Pawn brokering}

How does a pawn shop service a niche that commercial banking does not service? Jack Daugherty, the founder and C.E.O. of Cash America, the largest pawn chain in the U.S., remarked to a journalist, "I could take my customers and put them on a bus and drive them down to a bank and the bank would laugh at them. That is why they're my customers (Caskey, 1994)." The bank does not want these customers because they have high credit risk that would require collateral to mitigate. The loans are for small amounts, and this makes it not worth the bank's trouble to process the loans. The bank faces a usury ceiling that limits the amount of interest that the bank could charge. Additionally, the bank may have a problem holding small denomination assets as collateral as well as selling unclaimed assets.

\section{Credit Margins}

The expansion of credit margins tends to produce sustained adverse selection concerns for lenders. A bank's target customers may fit into the non-conforming market segment, because these borrowers may generate higher origination fees. A non-conforming borrower might be someone with slow credit or a high debt to income ratio, or the borrower might be self-employed and have little or no traceable income. A bank may market its sub prime mortgages using direct mail and telemarketing. The high interest rate and origination fees discourage borrowers who qualified for conforming mortgages that may have lower rates and fees at other lending institutions. For instance, a bank might buy consumer marketing lists that are composed primarily of weak credits, or a bank may target borrowers for whom they had originated their loans previously and then subsequently sold their loans to other sub prime lenders. These strategies may produce many unfruitful loan applications, however. If a bank had granted the borrower a second mortgage, then the bank may be marketing to a borrower who had refinanced to a threshold where the borrower did not have enough equity to take on an additional mortgage or to refinance the borrower's preexisting mortgage to lower the payments. To a bank's benefit, however, the bank may also find and process some applicants who could have taken a conforming mortgage from another bank if borrowers had known better. ${ }^{6}$

\section{Securitized Loans}

There is an adverse selection concern when an originator securitizes mortgages, too. A prospective buyer might assume that the originator may keep the better mortgages and sell the worse ones. This is a moral hazard concern for Fannie Mae and Freddie Mac, government sponsored enterprises that buy originated mortgages and then securitize them in the secondary market. Consequently, Fannie and Freddie often want an institution to sell them all loans that the institution originates. To protect themselves, Fannie and Freddie impose penalties on lenders when its purchased mortgages fail to meet a contracted benchmark standard based upon the performance of similar loans.

\footnotetext{
${ }^{6}$ This is a reverse moral hazard problem for borrowers. To mitigate this problem, Fannie Mae makes available a tool, called the Loan Prospector, that lets borrowers know whether they qualify for a conforming mortgage or not.
} 


\section{Seasoned Equity}

Why do established firms that issue new equity have returns that tend to under perform relative to the returns of comparable firms in their industry? Firms that issue new equity may do so because their managers feel it's the cheapest source of funds. This may mean that managers feel that the firm's equity is overvalued. Because financial markets know this, established firms are disinclined to issue new equity (Fazzari and Hubbard, 1988). Consequently, successful firms tend to prefer to use retained earnings to finance new projects. Thus, the firms that do issue seasoned equity tend to be poor performers.

\section{Extended Medical Insurance}

Why is extended medical insurance available to former employees so expensive to underwrite? Extended medical insurance policies have a history of generating high insurance claims per policy. Thus, actuaries need to charge a large premium for extended medical insurance. Many former employees will obtain health insurance from their new employer and will not seek more expensive extended medical insurance. Some former employees who do seek extended medical insurance may do so because they have existing medical conditions that might not be covered by their new medical insurance policy. This population is more expensive to insure because they are more expensive to care for. They require more medications, more tests and procedures, and more doctor visits than most other patients.

\section{Implementation Shortfall}

A mutual fund has not been able to consummate all its planned trades due, in part, to stock price change/liquidity issues. Perold (1988) uses the implementation shortfall, the difference in return between a theoretical paper portfolio and the implemented portfolio, as an assessment tool. Perold (1988) partitions the implementation shortfall into higher transactions costs to execute the planned trades and the opportunity costs of not transacting. The adverse selection stems from illiquidity, the inability to trade at the prevailing price when the market moves against a trade (Treynor 1981). This is when it is likely to be beneficial for the fund manager to trade. A large buy order at prevailing price could also reveal the belief of the manager that the security is undervalued. If other traders make inferences based on the actions of the manager, this might raise the price at which the manager can purchase the security. On paper the fund is able to execute a trade of $\$ 10 \mathrm{~mm}$ at the prevailing price. In practice, however, perhaps the fund may only purchase the first $\$ 1 \mathrm{~mm}$ immediately. If the manager placed a market order, then the remaining $\$ 9 \mathrm{~mm}$ of the order could execute at a less advantageous price. If the manager placed a limit order, then the remaining $\$ 9 \mathrm{~mm}$ of the order would not be executed at all. In some cases a trader may choose to delay a portion of his/her trade; in other cases the trade may never be consummated. In all cases, the fund manager will not achieve the paper strategy because of execution limitations.

\section{Exclusion}

Insurance exclusion discourages risky activity, because the activity undertaker cannot contract to transfer the risk from the activity to another entity. From the insurer's perspective, this reduces moral hazard. It also reduces adverse selection concerns. For instance, a builder might elect not to build homes in a severe flood plain if the builder knows that subsequent homeowners may not be able to purchase flood insurance. Thus, a builder might not be able to earn a reasonable profit and may elect to build homes elsewhere. Consequently insurance exclusion reduces the amount of flood insurance claims and adverse selection concerns, since there will be fewer homes located in severe flood plains and insurer will not underwrite insurance for many homes located in severe flood plains. 


\section{Assessment}

\section{Actuarial Models}

Actuarial methods are classical risk management techniques. They are based on simple ideas that have a sound scientific foundation. Actuarial techniques have been a pillar of the insurance industry for centuries. They have stood the test of time -- and we fully anticipate that they will continue to do so. Like Old Man River, the practice of actuarial models just keeps rolling along.

Actuarial models are robust because each observation does not have much influence on the estimates. Transparency makes them easy to audit. If a forecast goes sour, an investigator may pinpoint what went wrong in the model and correct the situation.

An investigator needs to assess that the observations in each risk class are reasonably homogenous with respect to the loss event. Further, an investigator may not have many options when estimating models to allow for time variation and so forth due to the pooling observations into a few risk classes. As a consequence trending might have a strong specification bias or suffer from risk class cohorts that are populated with only a few observations.

\section{Risk Classes}

We seek to partition our sample into relatively homogenous risk classes with respect to loss exposure. How do we do this? This is part of the 'art' of actuarial models. Perhaps, scientific theories, common sense, or past experiences show us the way. Otherwise, we might try exploratory data analysis techniques such as discriminant or cluster analysis on available data sets. ${ }^{7}$

For instance, most actuaries separate out sixteen-year-old boys from other auto insurance customers. Sixteen-year-olds are inexperienced drivers. Most sixteen-year-old boys are undergoing puberty and lack good judgment. Sixteen-year-old boys have a long documented history of high risk driving. Consequently, it makes sense to discriminate ${ }^{8}$ against sixteen-year-old boys and separate them out from other drivers and charge them higher premiums to reserve for the higher losses an actuary anticipates that they will generate. If an insurance company charged the same premium to all drivers, then they would likely garner an adverse selection of sixteen-year-old boys and other high risk drivers that might generate large losses to the detriment of the insurance company. Their competitors may benefit, however, because they may be left with a beneficial selection of less risky drivers to insure.

Similarly, the manufacturers of the Pontiac Firebird/Chevrolet Camaro ${ }^{9}$ and the Nissan $300 \mathrm{ZX}^{10}$ designed and marketed their automobiles to a customer base that was expensive to insure. They did an excellent job of identifying and providing the needs and desires of that market segment that wanted fast sports cars. Unfortunately, they created an adverse selection concern because the accident rate and damages for these cars were high. Consequently, the insurance premiums for these vehicles have tended to be quite high. This has left many in the target consumer base unwilling to purchase these automobiles, because they did not want to pay to insure them.

The advent of new data sets may induce changes to risk class partitions. For instance, when automobile repair centers computerized their records, it made it possible for an actuary to employ observations for the number

\footnotetext{
${ }^{7}$ The 'art' of choosing risk classes suggests that the underlying probabilities inherent in biased sampling of a heterogeneous population (conditional probabilities) are subjective. See Kane (1999B) for a discussion of this issue with respect to security price changes.

${ }^{8}$ We note that this kind of discrimination has an economic justification. We distinguish this discrimination from uneconomic discrimination which we define as discrimination that cannot be adequately supported by statistical inferences. We argue that competition may help to mitigate uneconomic discrimination, since a competitor may earn above normal profits catering to uneconomically discriminated against parties.

${ }^{9}$ http://www.hwysafety.org/news\%5Freleases/1997/pr091897.htm

http://www.hwysafety.org/vehicle\%5Fratings/ictl/ictl\%5Fsport.htm

${ }^{10} \mathrm{http}: / /$ www.hwysafety.org/vehicle\%5Fratings/ictl/previous/ictl\%5F0996.pdf
} 
of miles that a car is driven in a year to partition drivers, since many repair centers regularly record the odometer reading when servicing a vehicle. ${ }^{11}$

How might an investigator assess heterogeneity? As an illustration, we explore whether or not a proposed risk class used to set auto insurance premiums for a car model is also affected by the choice of color of the car. We suppose the frequency of accidents for each available factory color in the year 2001 is reported below:

\begin{tabular}{|c|c|c|}
\hline Color & Number of Cars & Accidents \\
\hline Red & 29,333 & 289 \\
\hline Blue & 16,325 & 164 \\
\hline White & 2,304 & 17 \\
\hline Brown & 5,421 & 22 \\
\hline Black & 38,740 & 405 \\
\hline Green & 1,256 & 13 \\
\hline Total & 93,379 & 910 \\
\hline
\end{tabular}

We perform a $\chi^{2}$-test at the $5 \%$ level for the null hypothesis that the probability of an accident is homogenous in the color of the car (Bernstein and Bernstein, 1999).

We have $6-1=5$ degrees of freedom. ${ }^{12}$

$\mathbf{H}_{\mathbf{0}}$ The probability of an accident is homogenous in the color of the car.

$\mathbf{H}_{\mathbf{1}}$ The probability of an accident is heterogeneous in the color of the car.

We compute the expected number of accidents under $H_{0}$.

$$
\begin{aligned}
& \chi^{2}=\sum \frac{(\text { observed }-\exp \text { ected })^{2}}{\exp \text { ected }} \\
& \chi_{5}^{2} \approx(289-285.8569)^{2} / 285.8569+(164-159.0909)^{2} / 159.0909+(17-22.45301)^{2} / 22.45301+ \\
& (22-52.8289)^{2} / 52.8289+(405-377.5303)^{2} / 377.5303+(13-12.24001)^{2} / 12.24001 \\
& \approx 0.03456+0.151481+1.324337+17.99055+1.998742+0.047188 \approx 21.54686
\end{aligned}
$$

\section{Color $\quad \underline{\text { Expected Accidents }}$}

$\begin{array}{ll}\text { Red } & 29,333(910 / 93,379)=285.8569 \\ \text { Blue } & 159.0909 \\ \text { White } & 22.45301 \\ \text { Brown } & 52.8289 \\ \text { Black } & 377.5303 \\ \text { Green } & 12.24001\end{array}$

\footnotetext{
${ }^{11}$ The existence of database induces privacy concerns - especially with medical records. Perhaps someone would not get an AIDS test, because they might fear that, by doing so, they might make their life insurance premiums too expensive. Further, because some diseases may be genetically related, there is the potential for forms of racial discrimination that is induced by access to medical records.

${ }^{12}$ Since we are using an average in our computations, we lose one degree of freedom.
} 
Since, $\chi^{2}>\chi_{5,0.05}^{2}{ }^{*}=11.07$ we reject $H_{0}$, and infer that the color of the car affects the probability of an accident.

\section{Frequency and Severity}

How do actuarial models work? We suppose that we have a loss event (death, credit default, auto accident ${ }^{13}$ etc.) history for a risk class of contracts (humans, borrowers, automobiles etc.). We suppose that we have data beginning in 2000 and that we are interested in a three year forecast of death starting in 2003 and continuing through the end of 2005. We suppose that we have classified the contracts into risk class cohorts at the start of the year.

\begin{tabular}{|c|c|c|c|c|}
\hline \multirow[b]{2}{*}{ Year } & \multirow[b]{2}{*}{$\underline{\text { Observations }}$} & \multicolumn{3}{|c|}{ Deaths } \\
\hline & & $\underline{\text { Year } 1}$ & $\underline{\text { Year } 2}$ & Year 3 \\
\hline 2004 & 567 & 11 & & \\
\hline 2003 & 591 & 2 & 31 & \\
\hline 2002 & 602 & 3 & 36 & 45 \\
\hline 2001 & 557 & 7 & 39 & 39 \\
\hline 2000 & 616 & 9 & 28 & 27 \\
\hline
\end{tabular}

How might we use these cohort observations to generate a forecast of survivorship? We average the proportion of survivorship in the cohorts for each year to form a first year forecast:

$\begin{array}{rll}567-11) / 567 & =556 / 567 & =0.9806 \\ (591-2) / 591 & =589 / 591 & =0.996616 \\ (602-3) / 602 & =599 / 602 & =0.995017 \\ (557-7) / 557 & =550 / 557 & =0.987433 \\ (616-9) / 616 & =607 / 616 & =0.98539 \\ \text { Average } & =0.989011\end{array}$

We employ the same method ${ }^{14}$ for years two and three:

$\begin{array}{cccc} & 0.944162 & & \\ 0.935216 & & 0.860465 \\ 0.917415 & & 0.847397 \\ & 0.939935 & & 0.896104 \\ \text { Average } & 0.934182 & \text { Average } & 0.867989\end{array}$

Next, we need to have some notion of losses given that a loss event (death, default, accident, etc.) has occurred. The expected loss may vary across risk classes and over time. For instance, we might suppose that losses that occur are $\$ 0.30$ in the first year, $\$ 0.40$ in the second year, and $\$ 0.50$ in the third year. What do we forecast (project in losses) if we make $\$ 10$ million in loans to this risk class?

$1-0.989011) *(10,000,000) *(0.30)$
$(0.989011-0.934182) *(10,000,000) *(0.40)$
$(0.934182-0.867989) *(10,000,000) *(0.50)$

\footnotetext{
${ }^{13}$ In property and casualty insurance, it may be possible to have more than one loss event during the term of the insurance. We could employ the same method for the probability of two losses, three losses, etc. We ignore this technicality for simplicity.

${ }^{14}$ We need to examine whether our estimated survival functions are non-increasing. It could happen that a survival function is decreasing due to averaging. If this is the case, we may set the survival function to be constant over the relevant time period.
} 
We forecast that we will have losses of $\$ 3,296.73$ in the first year, $\$ 219,315.40$ in the second year, and $\$ 330,967.20$ in the third year.

\section{Losses Given an Event:}

How does an investigator estimate losses given an event (death, default, etc.)? Risk class cohorts tend to be dependent - after all, the same observations may be in several risk class cohorts that are classified over different time periods. Consequently, many actuaries choose to use non-parametric and distribution-free statistical methods (Kane 2004).

We give an example of the sign-rank test which is used to assess whether or not the distribution of losses is drawn from the same underlying distribution for two different risk classes. ${ }^{15}$ The sign-rank test is a rank-order test to determine if a population median is equal to a hypothesized value. It is a nonparametric analogue of the one-sample t-test. We substitute a median for a mean. The null hypothesis is the median equals the hypothesized value. We subtract the hypothesized median from each observation in the sample. We rank observations in the sample in absolute value from 1 to $\mathrm{n}$. We average ranks for tied observations. We sum the ranks with positive scores, (W+), and sum the ranks with negative scores (W-). We consider all possible shuffled arrangements of the two samples. Under the null hypothesis, all shuffled arrangements of observations from both samples into synthetic samples that keep the same size as in the original samples, have an equal probability of occurring. We use this assumption operationally to calculate the probabilities that the test statistics, (W+), (W-), and Min $\{(\mathrm{W}+),(\mathrm{W}-)\}$, are as large as we have observed them. We define a p-value for each test statistic as the relative frequency shuffled arrangements with test statistics that are bigger than or equal to the test statistic from the observed sample (Kane 2004). These operational assumptions allow us to perform the analogous one-sided tests and two-sided tests to t-tests, respectively (Bernstein and Bernstein, 1999).

We suppose that we have two distributions of losses given an event from two risk classes, sample 1and sample 2, both with one hundred observations. We calculate the differences of the absolute value of percentage changes and rank the differences, and restore the sign of the differences of their corresponding ranks. We find that $\mathrm{W}+=1,827$ and $\mathrm{W}-=-3,223$. We perform a large sample Wilcoxon (sign-rank) test with $\alpha=0.01, H_{0}: \tilde{\mu}_{1}=\tilde{\mu}_{2} ; H_{1}: \tilde{\mu}_{1} \neq \tilde{\mu}_{2}$. We assume convergence under the central limit theorem to a normal distribution. We give the value of the test statistic.

$$
Z=\frac{W-\frac{n(n+1)}{4}}{\sqrt{\frac{n(n+1)(2 n+1)}{24}}}=\frac{1,827-\frac{100(100+1)}{4}}{\sqrt{\frac{100(100+1)(200+1)}{24}}}=\frac{-698}{290.84}=-2.4
$$

$Z_{\frac{0.01}{2}}^{*}=-2.57$. So we fail to reject the null hypothesis.

The level of significance is $P(Z<-2.4)=0.5-0.4918=0.0082$.

Thus, based solely on the result of this test, we would not use separate estimates for losses given an event for the two risk classes.

\footnotetext{
${ }^{15}$ There are other techniques for the two sample problem. For instance, Kane (1998) discusses the $L^{1}$ and $L^{\infty}$ (Kolmogorov-Smirnov) normed distribution-free tests.
} 


\section{POLICY DISCUSSION}

How can something so simple be so effective? Is this what insurance companies really do? Yes, the simple method is the underpinning of most insurance premium estimates. But it is dubious that such a simple technique can forecast very accurately. So what kind of built-in safety nets have evolved with actuarial methods? We note that the existence of built-in safety-nets suggests that these items cannot really be forecast that well.

The first built-in safety net is the mutual form of ownership where the policy holders own the company. This differs from a corporation or proprietorship. The mutual ownership structure makes sense in life and pension insurance, whereas a proprietorship or a corporation has less credible promises. What would happen if the sole proprietor did not live longer than the policy holders? Similarly there are problems with a corporation. What would happen if a corporation went bankrupt? The shareholders might use their limited liability to walk away from the companies long-term obligations to pensioners.

A second safety-net mechanism is price fixing. We argue that insurance tends to be predominately state regulated and not federally regulated to allow price fixing (Kane and Smith, 1997). Under the Sherman Antitrust Act, price fixing is illegal per se (1944 U.S. Supreme Court ruling against the South Eastern Underwriters Association). The McCarran-Ferguson Act of 1945 clarified the federal government's role in regulating insurance. This created pressure on states to change their insurance regulations to prevent federal challenges to price fixing. How might actuaries collude to fix insurance premiums? Actuaries may use the same model and the same data inputs to set premiums. Furthermore, there may be a state insurance commissioner who may make price fixing legal (Kane and Smith, 1997).

Why do actuaries tend to overcharge and then rebate? It is incentive compatible for an actuary to overcharge customers and then rebate surviving policyholders through lower premiums. It is difficult to know what a fair premium is, but it might not be difficult to know what a sufficient premium is. Consequently, actuaries may set premiums that systematically overcharge almost everyone. Further it is difficult for a beneficiary to argue ex post that an insured person has been overcharged for life insurance in the year the insured person has died. Overcharged policyholders who died have been removed from the mutual to the benefit of the survivors in the mutual.

Why might state insurance regulators be willing accomplices? There may be an economic justification for price fixing. Price fixing creates an incentive for companies to undertake loss prevention and control activities that might otherwise be public goods where the insurance company cannot capture enough of the benefits to justify their efforts (Kane and Smith, 1997). By allowing price fixing, insurance regulators have less worry about insurance companies failing due to competition. Regulators also limit the number of competitors. To protect their economic rents, insurance company managers may allocate more capital, too. Insurance policies may be available to anyone who wants one (Kane and Smith, 1997). Otherwise adverse selection concerns might cause some members of risk classes not to be able to obtain policies -- even though almost everyone will have to pay a higher premium than would be fair on an expected value basis. Inasmuch as an insurance commissioner is more likely to be held accountable for failed insurers than for premiums being too high, it is not surprising that many state insurance commissioners are willing accomplices to price fixing (Kane and Smith, 1997).

\section{CONCLUSION}

We used examples to help identify adverse (beneficial) concerns. We demonstrated that they are general problems. We showed how financial practitioners use actuarial models for assessment and forecasting applications. We discussed how insurance regulation has adapted to modeling limitations.

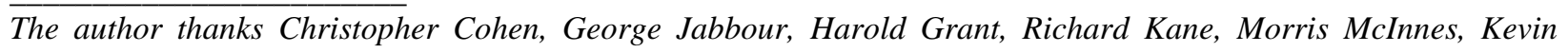
McLaughlin, Michael Smith, Morris Weisman, Xiaohong Yang, Liwen Yen, and participants of the 2004 IBER conference for comments and suggestions that have improved this manuscript. 


\section{REFERENCES}

1. Akerlof, George, 1970, "The Market for 'Lemons': Quality Uncertainty and Market Mechanism," Quarterly Journal of Economics, vol. 84: pages 488-500.

2. Bernstein, Ruth and Stephen Bernstein, 1999, Schaum's Outline of Theory and Problem of Elements of Statistics II: Inferential Statistics, McGraw-Hill, New York.

3. Mark S. Blodgett and Stephen A. Kane, 2003, "Global Corporate Governance: Implications For A Functionally Harmonized Legal Infrastructure,” Journal of Business \& Economics Research Vol. 1(6) pp. 19-26.

4. Caskey, John 1994, Fringe Banking: Check-Cashing Outlets, Pawnshops, and the Poor, Russell Sage Foundation, New York.

5. Coffee, John, 1999, "The Future is History: The Prospects for Global Convergence in Corporate Governance and its Implications," Northwestern University Law Review, spring, pages 641-707.

6. Fazzari, Steven and R. Glenn Hubbard, 1988, "Financing Constraints and Corporate Investment," Brookings Papers on Economic Activity, Vol. 1: pages 143-195.

7. Kane, Stephen and Michael Smith, 1997, "Price Fixing and the Rating Bureaus: The Southeast Underwriters from 1913-1943," presented at the Insurance and Risk Management conference.

8. Kane, Stephen, 1998, "Normed Distribution-Free Testing for Identically Distributed Residuals," Advances in Financial Planning and Forecasting, Vol. 8, pages 95-111.

9. Kane, Stephen 1999A, "Teaching Principal Agent Problems Using Examples from Popular Music," Financial Practice and Education, pp. 116-120.

10. Kane, Stephen, 1999B, "What Happened to the Utility Functions? Imprecise Expectations of Security Prices," International Review of Financial Analysis, Vol. 8, pages 165-176.

11. Kane, Stephen, 2004, "Scientific Methods in Finance," International Review of Financial Analysis, Vol. 13, pp. 105-118, 2004.

12. Kane, Stephen, Laosinchai, Parames, and Mark Muzere, 2003, "Bank Reserves and Liquidity," presented at the 2003 Applied Business and Economic Research Conference in Acapulco Mexico.

13. Kane, Stephen and Mark L. Muzure, 2004, "Asset Securitizations in the Banking Industry" forthcoming in International Business \& Economics Research Journal.

14. Perold, André F., 1988, "The Implementation Shortfall: Paper vs. Reality." Journal of Portfolio Management 14, no. 3 (spring), pages 4-9.

15. Reichheld, Fredrick, 2001, The Loyalty Effect: The Hidden Force Behind Growth, Profits, and Lasting Value, Harvard Business School, Cambridge MA.

16. Treynor, Jack, 1981, "What Does It Take to Win the Trading Game?" Financial Analysts Journal January/February. 